\title{
Study of maternal and perinatal outcome of referred patients in tertiary health centre
}

\author{
Jyotsana*, Lalit D. Kapadia, Hafsa Vohra
}

Department of Obstetrics and Gynecology, B.J. Medical College, Ahmedabad, Gujarat, India

Received: 16 September 2017

Accepted: 26 October 2017

\section{*Correspondence:}

Dr. Jyotsana,

E-mail: vivacious.gl@gmail.com

Copyright: (C) the author(s), publisher and licensee Medip Academy. This is an open-access article distributed under the terms of the Creative Commons Attribution Non-Commercial License, which permits unrestricted non-commercial use, distribution, and reproduction in any medium, provided the original work is properly cited.

\begin{abstract}
Background: Referral services for identification and referral of high risk pregnancies are an integral part of maternal and child health services. The aim of this study was to review the pattern of obstetric cases referred to tertiary care center, to identify their clinical course, mode of delivery, maternal and perinatal outcomes.

Methods: It is a prospective observational study carried out from January 2017 to July 2017. Study population was all Obstetrics patients referred to Department of Obstetrics and Gynecology of B.J Medical College, Ahmedabad, Gujarat, India a tertiary care center during the study period.

Results: The total number of referred cases in above study period was 100 . Mode of transport used by the referred patients was by 108 ambulances (75\%) and private vehicles (25\%). Most common diagnosis at the time of referral was hypertensive disorders of pregnancy (31\%). Out of the total referred cases, $57 \%$ had vaginal delivery, $42 \%$ had caesarean section. Hypertensive disorders of pregnancy constitute the leading cause of maternal deaths amongst the referred cases.

Conclusions: The present study has shown that inadequate antenatal and intra-natal care at the periphery level is responsible for increased maternal and perinatal morbidity and mortality. Even today, hypertensive disorders of pregnancy are the leading cause of maternal mortality. Health education to the community will definitely reduce maternal and perinatal morbidity and mortality.
\end{abstract}

Keywords: Maternal morbidity and mortality, Maternal and fetal outcome, Obstetrics referrals, Perinatal morbidity and mortality

\section{INTRODUCTION}

The referral system is particularly important in pregnancy and childbirth for providing access to Emergency Obstetric Care. Timeliness and appropriateness of referral is an important factor in the ultimate outcome of the patients. ${ }^{1}$ Linking the primary, secondary and tertiary levels of care are an essential element of primary health care. $^{2}$

Although most obstetric complications (defined as acute conditions such as postpartum hemorrhage, sepsis, eclampsia, and obstructed labor that can cause maternal death cannot be predicted, the majority can be treated with timely provision of a package of evidence-based interventions known as emergency obstetric care (EmOC). ${ }^{3,4}$

The availability of EmOC is considered to be an indicator of how well a health system is prepared to manage conditions leading to acute maternal morbidity and mortality. ${ }^{5-7}$

Timing process is critical in preventing maternal deathand disability. Maternal mortality can be significantly reduced if a system is in place to recognize 
problems promptly and to transport a woman to a health facility where she can receive appropriate and timely treatment. ${ }^{8-10}$

With this background, present study was undertaken to evaluate the pattern of obstetric cases referred to tertiary teaching hospital and maternal outcomes amongst referred patients.

\section{METHODS}

It was a prospective observational study. This study was conducted from January 2017 to July 2017. Randomly selected 100 cases referred to the Department of Obstetrics and Gynecology Civil Hospital Ahmedabad, B.J. Medical College Ahmedabad, a tertiary care center during the study period.

A preformat was designed specially to cover all the aspects of referral including cause, place, and maternal outcome including salient features of history, examination, baseline and specific laboratory investigations. Ultrasound was carried out in relation to clinical condition of patient. Management of the patient was documented in detail. Mode of delivery was noted. It also included perinatal outcome. Fetal outcome was noted regarding gestational age, live or stillbirth, Birth weight, NICU admissions and reasons for NICU admission, clinical course of the baby before discharge of mother and if any complications occurred.

\section{RESULTS}

Current study included 100 obstetric cases referred to the Department of Obstetrics and Gynecology, Civil Hospital Ahmedabad, B.J. Medical College during the study period.

Maximum number of cases in the present study was in the age group 20-30 years, comprising $71 \%$ of total cases, $22 \%$ were more than 30 yrs. while $7 \%<20$ yrs. $50 \%$ of the total referred were multigravida while $46 \%$ were primi gravida with $4 \%$ grand multigravida.

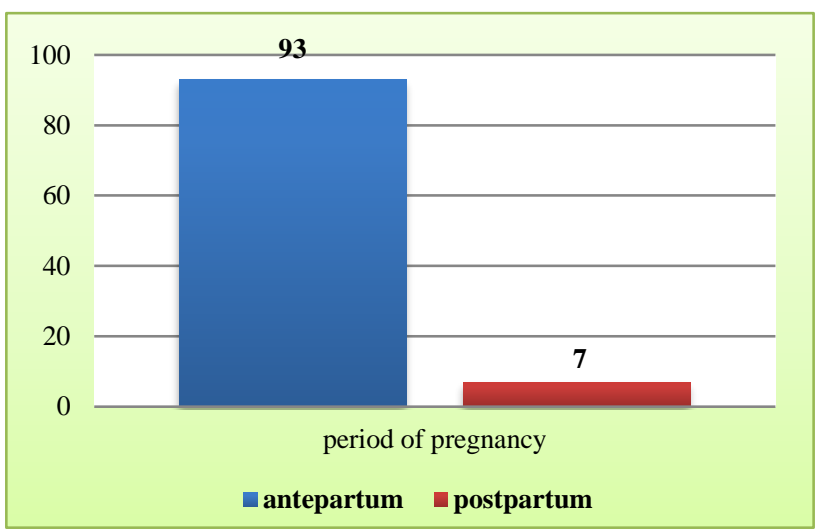

Table 1: According to period of pregnancy.
$90 \%$ of the cases in our study were referred in the antepartum period and $10 \%$ in the post partum period to our hospital (Figure 1).

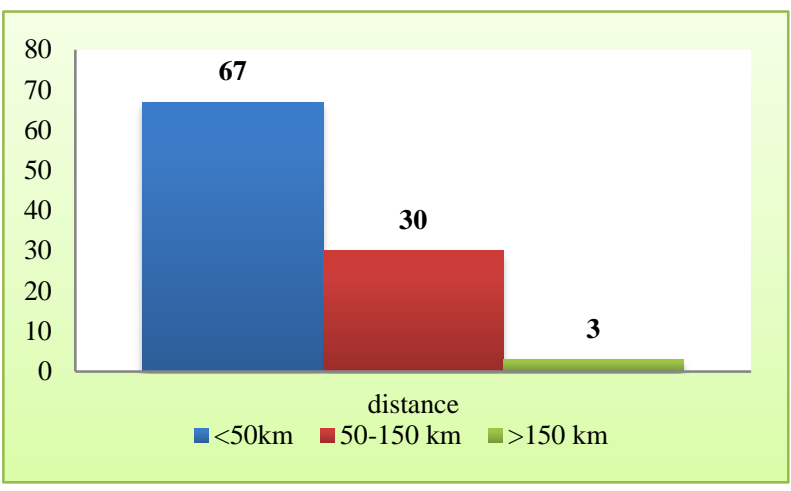

Figure 2: Distribution of cases according to distance from referral center.

$67 \%$ of cases were referred to our hospital from $<50 \mathrm{~km}$ distance (Figure 2).

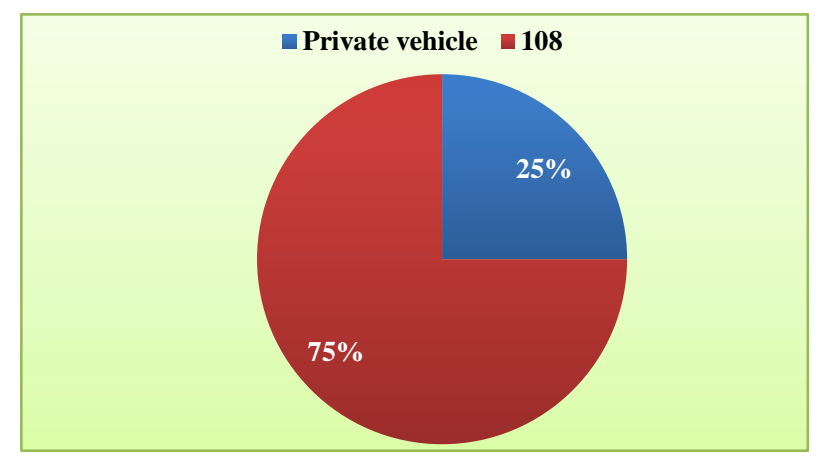

Figure 3: Mode of transport.

Mode of transport used by the referred patients was by $108(75 \%)$ and $25 \%$ by private vehicles (Figure 3 ).

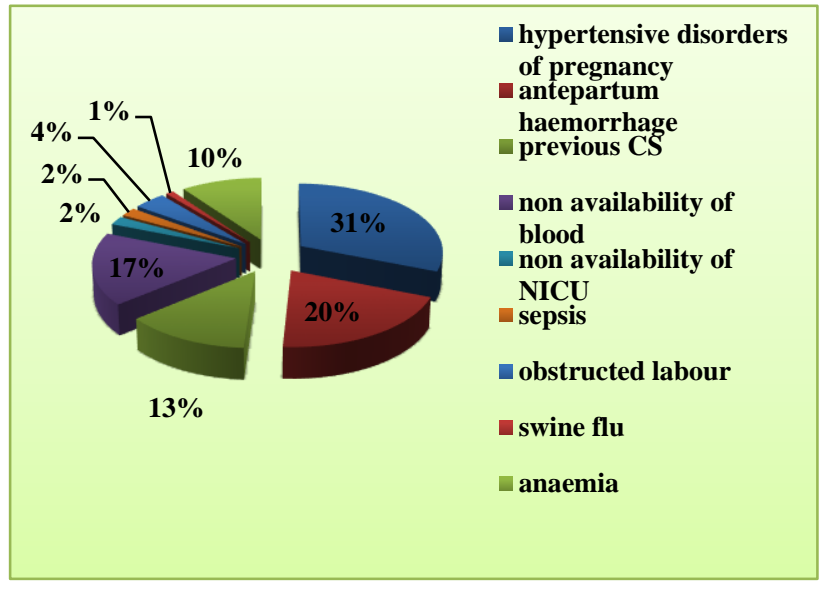

Figure 4: Causes of referral.

Hypertensive disorders of pregnancy (31\%) followed by antepartum hemorrhage $(20 \%)$ were the major causes of referral to the tertiary care center. $10 \%$ cases were 
referred in view of anemia followed by $18 \%$ who were referred for non availability of blood bank facilities and $17 \%$ for previous caesarian sections (Figure 4).

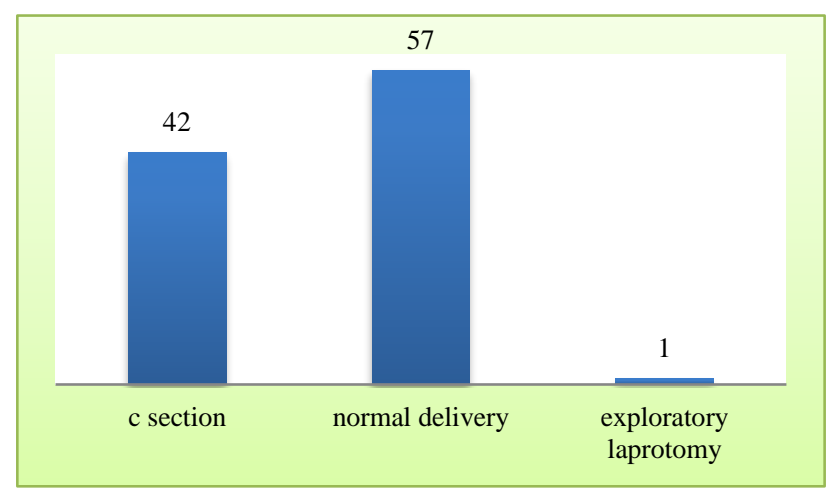

Figure 5: Mode of delivery.

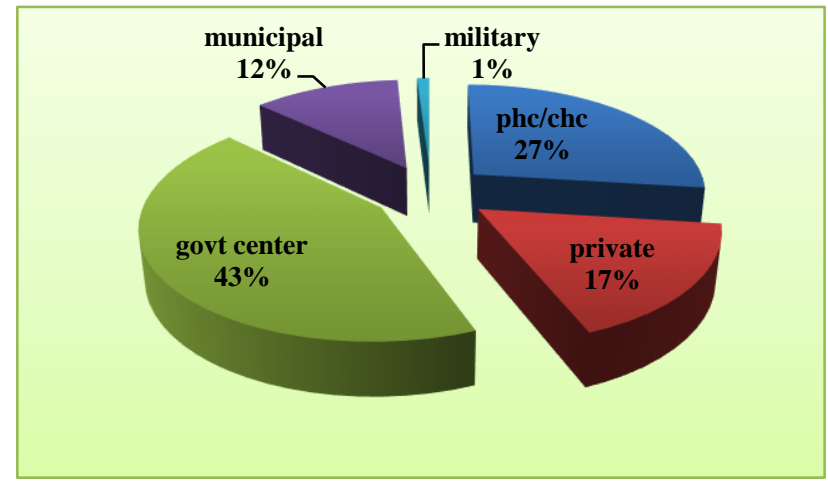

Figure 6: Source of referral.
Out of total referred cases, $51 \%$ had vaginal delivery (either spontaneous or induced), $41 \%$ had caesarean section and $7 \%$ were managed conservatively (delivered outside). $1 \%$ had laparotomy (Figure 5).

Total $30 \%$ had referral-arrival interval up to 2 to 4 hours when the distance was less than $50 \mathrm{~km}$. Only $5 \%$ cases reached within 4-6 hours, distance being more than 150 km (Table 1).

Table 1: Referral arrival interval.

\begin{tabular}{lll} 
Referral arrival interval & Number of cases & $\%$ \\
\hline Up to 2 hours & 30 & $30 \%$ \\
\hline 2-4 hours & 65 & $65 \%$ \\
\hline $4-6$ hours & 5 & $5 \%$ \\
\hline
\end{tabular}

$98 \%$ cases were referred with a referral slip and only $2 \%$ cases came without slip.

Total 5 maternal deaths were reported during the study period. DIC and postpartum hemorrhage in patients of eclampsia constitute leading cause of maternal death amongst referred cases.

Out of $57 \%$ normal delivered $45.6 \%$ newborns were alive and healthy, $19.2 \%$ were stillborn, $12.2 \%$ died, $31.5 \%$ had NICU admission and $68.4 \%$ were discharged well. Out of $42 \%$ delivered by caesarian section $47.6 \%$ newborns were alive and healthy, $9.52 \%$ were stillborn, $11.9 \%$ died, $45.2 \%$ had NICU admissions and $78.5 \%$ were discharged well (Table 2).

Table 2: Perinatal outcome.

\begin{tabular}{|llllll|}
\hline Mode of delivery & Alive and healthy & Stillbirth & Died & Nicu admission & Discharged well \\
\hline Normal delivery $(\mathrm{n}=57)$ & $26(45.6 \%)$ & $11(19.2 \%)$ & $7(12.2 \%)$ & $18(31.5 \%)$ & $39(68.4 \%)$ \\
\hline Caesarian section $(\mathrm{n}=42)$ & $20(47.6 \%)$ & $4(9.52 \%)$ & $5(11.9 \%)$ & $19(45.2 \%)$ & $33(78.5 \%)$ \\
\hline Exploratory laparotomy $(\mathrm{n}=1)$ & 1 & & & 1 & 1
\end{tabular}

\section{DISCUSSION}

Timeliness and appropriateness of referral are a challenge to obstetricians, since the delay in referral affects the maternal and perinatal outcome adversely, hence identification of at risk patients and obstetric emergencies and timely referral is of immense importance. ${ }^{11}$

In present study highest references $43 \%$ are from government medical college followed by the $\mathrm{PHC} / \mathrm{CHC}$ $(27 \%)$ followed by from private sector $(17 \%)$, which reflects the fact that our institute is situated in urban slum area, which constitute low and middle socio economic status population, which prefer treatment from government facility rather than private sector, as it is substantially costlier. In the present study, maximum number of patient $(71 \%)$ was in the 20-30years of age group. Morsheda Banu et al; in assessing showed that overall age distribution in majority $(74 \%)$ of the respondents were between 20-35 years. ${ }^{13}$ In present study, majority of patients were primigravida (46\%), which is comparable. ${ }^{14}$ Morsheda Banu et al; had found that around $50 \%$ of the women were primigravida.

In present study, $67 \%$ cases were referred from within 50 $\mathrm{km}$ distance, $30 \%$ cases travelled $50-150 \mathrm{~km}$ distance before reaching the hospital and $3 \%$ case travelled more than $150 \mathrm{~km}$ distance before reaching our hospital. Sakhare AP et al observed that $65 \%$ cases travelled more than $50 \mathrm{~km}$ distance before reaching to hospital and had 
increased incidence of intra operative complications and haemorrhage. ${ }^{15}$

In the present study the highest no of cause of referral is due to hypertensive disorders $(31 \%)$ anemia (19\%) while in the study done by Patel $\mathrm{HC}$ et al; causes of referral were preeclampsia (16\%), MSL (5\%). ${ }^{17}$ This may be not only due to unavailability of blood transfusion facilities in case of severe anemia at primary health care and community health care, but also cost factor in case of referral from private sectors. Rathi et al noted that majority of the cases were referred for hypertensive disorders of pregnancy $(26 \%)$, preterm labor $(26 \%)$, and medical disorders complicating pregnancy $(21 \%){ }^{16}$

The majority of patients $75 \%$ utilize 108 vehicles from referral facility and $25 \%$ used private vehicles. Arranging a private vehicle when faced with obstetric emergency necessitating referral takes time and cost money. This data shows improvement in transportation facilities for the referred patients as compared to past, due to increased availability of transport because of the new venture by Gujarat government like '108'.

Although $67 \%$ of referred patients had a distance $<50$ kms from medical college, only $30 \%$ patients reached to the medical college up to 2 hours. $65 \%$ of the patients took a long time of up to 4 hours to reach medical college after referral. The referral -arrival interval is long, which leads to poor maternal and perinatal outcome. This delay is due to lack of transport, lack of money, and ignorance of warning signs, poor road structures, and lack of local support.

Previous caesarean section was the cause of reference in $17 \%$ of cases in our study; while in study conducted by Khatoon A et al, previous caesarean section was the cause of reference in $15 \%$ of cases. ${ }^{13,18}$ The patients with previous caesarean section are referred to higher centers from $\mathrm{PHC} / \mathrm{CHC}$ due to unavailability of operation theatre, gynecologists, anesthetics, trained staff or basic infrastructure deficits.

In present study, 51\%-referred cases had vaginal delivery (either spontaneous or induced), 39\% had caesarean section and $7 \%$ (delivered outside either by CS or vaginal delivery) cases were managed conservatively. The commonest indication of caesarean section amongst referred patients was fetal distress. ${ }^{13,19}$ Sorbye et al found that referral status contributed substantially to the increased caesarean section rate, which was $55 \%$ in formally referred. ${ }^{20}$ In present study, $39 \%$ referred cases underwent caesarean section so we can conclude that rate of caesarean section is substantially high in referred cases.

The leading causes of maternal mortality are obstetrical hemorrhage $(5 \%)$ and DIC $(3 \%)$ in present study. Dilpreet et al.; found in their study hemorrhage as the leading cause of maternal death. Among the indirect causes malaria hepatitis (2\%) and pulmonary tuberculosis $(1 \%)$ are the leading causes of maternal death. Treatment of hepatitis in antenatal care and primary management of hemorrhage, including administration of fluids, uterotonics, suturing of tears at referring center will help in reducing mortality due to hemorrhage.

Causes of stillbirth in vaginal delivery were due to maternal reasons like hypertensive disorders of pregnancy, severe anemia, and antepartum hemorrhage while in caesarean births causes were same too. $31.5 \%$ vaginally delivered babies were shifted to NICU of which $68.4 \%$ were healthy on discharge and rest $12.2 \%$ died. $43.9 \%$ neonates delivered by caesarean section was shifted to NICU of which $78 \%$ were healthy on discharge and $12 \%$ were died.

Most of NICU shifted babies delivered by the patients, who had hypertensive disorders of pregnancy, fetal distress, PROM, antepartum hemorrhage, preterm labor pains, and obstructed labor. Main causes of NICU admission were respiratory distress due to meconium aspiration syndrome, birth asphyxia, preterm, septicemia and neonatal jaundice. Rathi $\mathrm{C}$ et al in their study reported $62.37 \%$ babies with live birth required NICU, $37.67 \%$ of live born babies were alive and healthy, still birth was $9.09 \% .^{22}$

Patients are referred to higher centers when either it is high-risk pregnancy or when conduction of normal vaginal delivery is difficult in primary set up. This may be the cause of higher caesarean section rate among referral patients. Delay in referral of complicated cases from our peripheral health centers, which could be due to lack of adequate transport facilities or trained personnel in PHC/CHC. Delay in referral is a big contributing factor for adverse maternal outcome.

\section{CONCLUSION}

Timely referrals with detailed referral slips imparting information regarding treatment received at the referring hospital might help in early and optimal intervention so as to reduce maternal and perinatal mortality. Moreover, a structured referral system would help both patient and doctor in providing essential lifesaving care.

Hypertensive disorders of pregnancy have been the commonest cause of referral among high-risk obstetric patients, which can be better dealt at tertiary care center. Also, administration of $1^{\text {st }}$ dose of magnesium sulphate must be done in all cases of eclampsia and severe preeclampsia prior to referral.

Health education to the community, better antenatal care up to grass root level, emergency intranatal care, availability of services of skilled birth attendants at the time of child birth, well organized first referral center with better transportation facility, availability of blood round the clock, anesthetic facilities and availability of 
specialist in the field of obstetrics at the referral unit will definitely reduce maternal morbidity and mortality.

Funding: No funding sources

Conflict of interest: None declared

Ethical approval: The study was approved by the Institutional Ethics Committee

\section{REFERENCES}

1. Park K. Textbook of Preventive and Social Medicine 17th ed. Jabalpur. Banarasidas Bhanoj Publishers; 2000:632.

2. Thaddeus S, Maine D. Too far to walk: maternal mortality in context. Soc Sci Med. 1994;38:10911110.

3. Brun JL, Billeaud C, Elleau C, Guyon F, Roux D, Dallay D et al. Maternal transport to the Bordeaux University Hospital: a retrospective study of 263 cases (1996-1998). J Gynecol Obstet Biol reprod. 200;29(4):414-22.

4. Swain S, Prakash A. Utilisation of referral services by high risk pregnant population in rural Varanasi. Indian J Matern Child Health. 1992;3(3):74-6.

5. 5.Koblinsky M, Chowdhury ME, Moran AC, Ronsmans C; Maternal morbidity and disability and their consequences: neglected agenda in maternal health. J Health Popul Nutr. 2012;30:124-30.

6. Lee AC, Lawn JE, Cousens S, Kumar V, Osrin D, Bhutta ZA, et al. Linking families and facilities for care at birth: what works to avert intrapartum related deaths? Int J Gynecol Obstet. 2009;107(1):65-8.

7. World Health Organization. Monitoring the building blocks of health systems: a handbook of indicators and their measurement strategies. Geneva: WHO;2010.

8. Travis P, Bennett S, Haines A, Pang T, Bhutta Z, Hyder AA, et al. Overcoming health systems constraints to achieve the millennium development goals. Lancet. 2004;364:900.

9. Paxton A, Bailey P, Lobis S; The United Nations process indicators for emergency obstetric care: reflections based on a decade of experience. Int $\mathbf{J}$ Gynecol Obstet. 2006;95:192-208.

10. WHO. Mother-Baby Package: Implementing Safe Motherhood in countries. 1994. Geneva: WHO/FHE/MSM/94.11.

11. Puri A, Yadav I, Jain N. maternal mortality in an urban tertiary care hospital of North India. J Obstet Gynecol India. 2011;61(3):280-5.
12. Morsheda B, Shamsun N, Hashima EN. Assessing the MANOSHI referral system addressing delays in seeking emergency obstetric care in Dhaka's. Slums. MANOSHI Working Paper Series ManoshiWP10:1-36 published by ICDDR, B, BRAC 2010:10.

13. Gupta PR, Chaudhary SN, Gonnade NV. Maternal and fetal outcome in referred patients to tertiary care center. Sch J App Med Sci. 2016;4(5C):1624-63.

14. Devineni K, Sodumu N. A study of spectrum of referral pattern at a tertiary teaching hospital towards better obstetric care. IAIM. 2016;3(8):193-8.

15. Sakhare AP, Thakare P. Outcome of caesarean delivery in rural obstetric referrals, $51^{\text {st }}$ Conference AICOG; 2008.

16. Vinayak NM, Panditrao SK, Ramkrishna MA Critical study of referrals in Obstetric Emergencies. J Obstet Gynecol India. 2004;54(3):258-9.

17. Patel HC, Singh BB, Moitra M, Kantharia SL. Obstetric referrals: scenario at a primary health centre in Gujarat. Natl J Community Med. 2012;3(4):711-4.

18. Khatoon A, Hasny SF, Irshad S, Ansari J. An audit of obstetrics referrals to Abbasi Shaheed Hospital. Pak J Surg. 2011;27(4):304-8.

19. Goswami D, Makhija A. A study of high risk obstretic referrals to tertiary care hospital in Garhwal, Uttarakhand. IJSR. 2015;4(10):1091-5.

20. Sorbye IK, Vangen S, Oneko O, Sundby J, Bergsjo P. BMC Pregnancy and Childbirth. Caesarean section among referred and self-referred birthing women: a cohort study from a tertiary hospital, north eastern Tanzania. BMC Pregnancy Childbirth. 2011;11(55):1-10.

21. Maskey S. Obstetric referrals to a tertiary teaching hospital of Nepal. NJOG. 2015;19(1):52-6.

22. Begum S, Aziz-un-Nisa I. Analysis of maternal mortality in a tertiary care hospital to determine causes and preventable factors. J Ayub Med Coll Abbottabad. 2003;15(2):49-52.

Cite this article as: Jyotsana, Kapadia LD, Vohra H. Study of maternal and perinatal outcome of referred patients in tertiary health centre. Int J Reprod Contracept Obstet Gynecol 2017;6:5363-7. 